Témoigner Témoigner. Entre histoire et mémoire

Getuigen Revue pluridisciplinaire de la Fondation Auschwitz

$123 \mid 2016$

Traduire le témoignage

Le Verfügbar aux enfers: interview met Marion Pillé

Entretien avec Marion Pillé

Daniel Weyssow

Traducteur : Gorik de Henau

(2) OpenEdition

Journals

Édition électronique

URL : https://journals.openedition.org/temoigner/5090

DOI : $10.4000 /$ temoigner.5090

ISSN : 2506-6390

Éditeur :

Éditions du Centre d'études et de documentation Mémoire d'Auschwitz, Éditions Kimé

Édition imprimée

Date de publication : 1 octobre 2016

Pagination : 23-29

ISBN : 987 2-9600926-4-6

ISSN : 2037-4183

Référence électronique

Daniel Weyssow, «Le Verfügbar aux enfers: interview met Marion Pillé», Témoigner. Entre histoire et

mémoire [Online], 123 | 2016, Online op 02 novembre 2021, geraadpleegd op 04 novembre 2021. URL: http://journals.openedition.org/temoigner/5090 ; DOI: https://doi.org/10.4000/temoigner.5090

Tous droits réservés 


\section{LE VERFÜGBAR AUX ENFERS INTERVIEW MET MARION PILLÉ}

MUZIEK Op 21 oktober 1943 wordt Germaine Tillion wegens verzetsactiviteiten naar Ravensbrück gedeporteerd. Door de solidariteit van haar kameraden slaagt ze in oktober 1944 in een onvervalst waagstuk waar de doodstraf op staat, namelijk schrijven. Ze is ervan overtuigd dat humor en inzicht in hun omgeving voor de gedeporteerden de laatste bescherming bieden tegen ontmenselijking. Daarom beschrijft ze hun leefomstandigheden in een compromisloze operette: Le Verfügbar aux enfers.

De operette wordt nu in november 2016 opgevoerd in het Brusselse Théâtre Marni. We hadden een gesprek met regisseur Marion Pillé, twee maanden nadat haar gezelschap Les Souffleuses de Chaos het work-in-progress voorstelde, meer bepaald op 11 november 2015 in het Maison de la Création. Op de uitnodiging prijkte volgende boodschap: 'Op de met afgeschoren haren bestrooide arena van een macaber, wrang grappig circus zingen en dansen vier actrices in een poging om dood en barbarij te tarten.

$\rightarrow$ Interview afgenomen door Daniel Weyssow

op dinsdag 19 januari 2016 in de lokalen van de Stichting Auschwitz Vertaling: Gorik de Henau

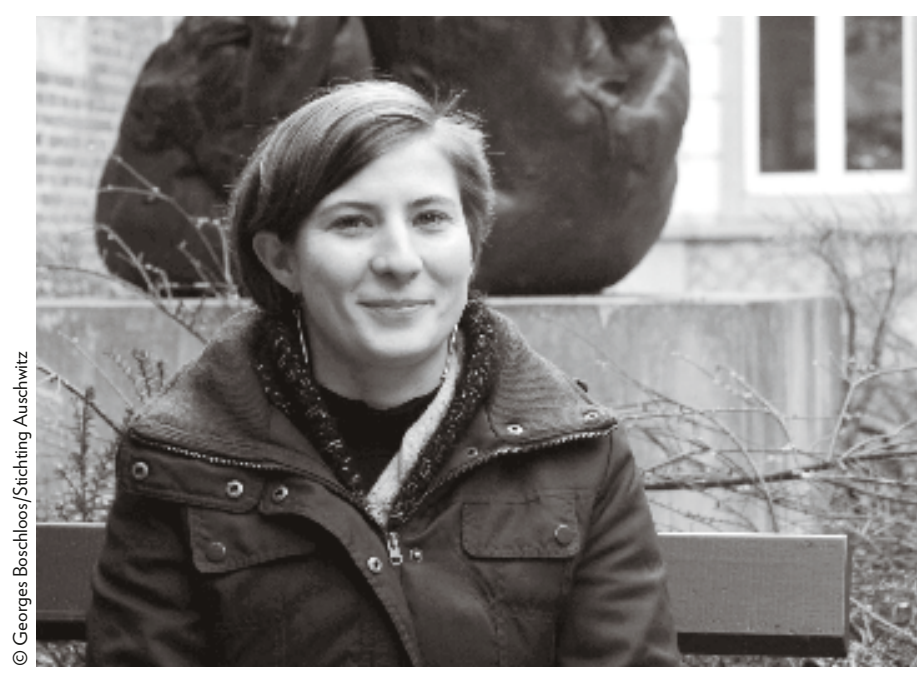

Je opleiding vond hoofdzakelijk plaats in twee instellingen in Frankrijk en België, de Cours Florent in Parijs en het INSAS in Brussel, waar je in 2012 afstudeerde. Voor Le Verfügbar aux enfers: une opérette à Ravensbrück van Germaine Tillion moest je over een behoorlijke bagage beschikken, want het bleek een complexe zaak om dit subtiele stuk te ensceneren en te vertolken. Gaat het om de eerste voorstelling van je gezelschap?

Marion Pillé: Nee, het is onze tweede voorstelling. Maar ik wilde al heel lang aan de slag met Le Verfügbar aux enfers. Het was trouwens mijn afstudeerproject aan het INSAS, maar vanwege de toenmalige reacties moest ik eerst iets lichters gaan doen en een ander project ondernemen.

Vonden je docenten dat je nog niet klaar was voor een dergelijk afstudeerproject?

Ze zeiden dat ik het project, zoals ik het zag, niet tot een goed einde kon brengen, toch niet voor mijn veertigste... 
Waarom?

Aan het INSAS concipieerde en presenteerde ik een fragment van dertig minuten, dat ongeveer overeenstemde met aktel. We hadden een paar dingen weggelaten om tot een coherent geheel te komen. Er waren veel misverstanden, ook bij de studenten, meer bepaald over de wenselijkheid om de concentratiekampproblematiek vandaag de dag aan te pakken. Maar toen al, in 2012, leek me dat noodzakelijk. Ik vond het van essentieel belang om de kwestie van het nazisme aan essentieel belang on de kwestie van het nazisme aan te kaarten. Gezien de actualiteit begrijpen de mensen meter me vier jarover mo 'm, thw llem rer meken met die haat jegens de ander

De commentaren sloegen dus op de ontvankelijkheid van het onderwerp, niet op het stuk zelf?

In de eerste plaats op het onderwerp, vervolgens op de vorm. Veel mensen vroegen me waarom ik ee stuk wile opvoeren dat de auteur maar heel laat voor van verraad om het stuk te brengen.

Zodra Germaine Tillion haar tekst vrijgaf, werd de operette opgevoerd.

Ja. En ze was aanwezig bij de première, in juni 2007 in het Théâtre du Châtelet.

Ze ging er dus mee akkoord dat het werk werd opgevoerd?

Absoluut... Als ze had geweigerd, dan had ik het niet gedaan. Volgens mij lag het probleem elders.

Waarom was de operette in de lade blijven liggen?

Een van de redenen die Germaine Tillion aanhaalt waarom ze Verfügbar niet gepubliceerd had, was de res dat het publiek haar gebruikvan humor niet zou begrijpen. Ze was bang dat de lezers de ernst van de levensomstandigheden in de kampen zouden relativeren alsje die methumor en liedjes kon vertellen. Waarschijnlijk speelde ook het naoorlogse negationisme een overtuigde haar door ann te voeren dat het mogelijk

via de tekst een waarachtigbeeld van hun ervaring te schetsen.

Een paradox en complicerende factor in heel dit werk dat het niet werd geschreven om buiten de kampcontex te worden vertoond. Tillion wilde haar lotgenoten opmonteren door het functioneren van het kamp te analyseren 政 de moeilijke omstandigheden. Buiten de kampcontext kan de tekst problematisch worden, aangezien hij tot stand kunver dus inge publiek, de plaats van de gedeporterden in het stuk innemen? Hoe terwijl die eigenlijk alleen voor hen waren bedoeld?

Dat is waar, een van de problemen is dat het publiek dat we beogen helemaal niet overeenstemt met het oorspronkelijke dolpuliek ove een tekstvoor'ingewijden', die precies weten waar het over reven voor personen dieluistergemen whe want het gat om een tekst van god wedeporteerden De facto speelden ze herden voor lazen hem mar hij is in speelden ze hen nooit, ze worden gespeld en beluisterd door cenzelf mensen. Hoe kun je dat groepsgevoel nu groep creëren?

Het eerste probleem voor de actrices was de vraas hoe ze gedeporteerden moesten vertolken, maar ik wilde juist niet dat ze die rol speelden. Ik bedacht dat we die materialisering konden bereiken via marionetten, goed beseffende dat ze alleen maar getuigen zijn van geschreven woorden. Daarnaast waren er de beschiift Charte Delbo. K vind dat ze heel moo beschrijt hoe ze zich tot haar Auschwitz-dubbelganger verhoud. gelde lichw. Zn na har terugkeer kon ze zichergelde lichaam. En na haar terugkeer kon ze zichzel alleen maar in het kamp voorstellen. Dat de mensen niet zagen dat ze bijna dood was, daar kon ze maar niet bij.Ze Ze zijle zever met aan haar zijde haar gedeporteerde dubbelganger,

Ik vond het ook belangrijk te begrijpen dat de gedeporteerden door hun traumatische herinneringen soms moellijkheden ondervonden in het dagelijks.

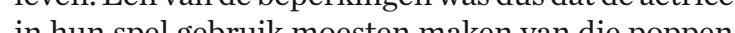

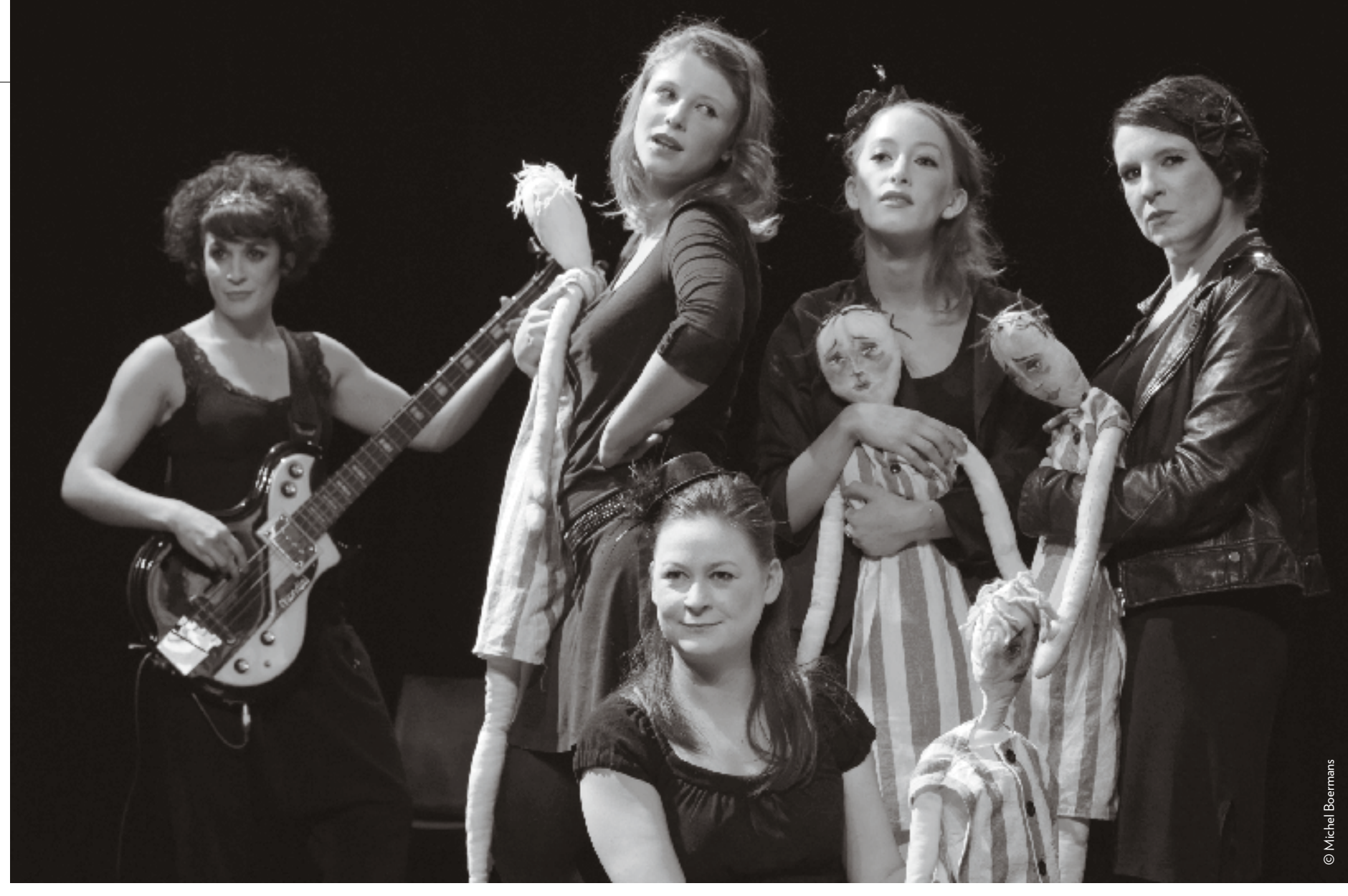

marionetten, met een lengte van 1,20 meter. De actrices hebben ze altijd bij zich en moeten er goedschiks en kwaadschiks mee omgaan, want ze nemen te veel plaats in, soms zelfs alle plaats. Ze zijn er altijd en mogen nooit worden neergezet, hoewel ze daar strikt genomen voor gemaakt zijn.

Hoe kreeg je interesse voor het werk van Germaine Hoe kreeg je interesse voor het werk van Germaine
Tillion en Le Verfügbar aux enfers? Hoe kwam je met de Tillion en Le Verfügbar aux enfers? Hoe kwam je met de
tekst in contact en wat deed je om je hem eigen te maken?

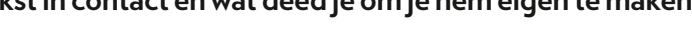

Helemaal in het begin wilde ik het verhaal van mijn grootvader neerschrijven, maar het bleek moeilijk on dat naar de planken te vertalen of aan acteurs toe te vertrouwen. Er was een bepaalde intimiteit waarvan ik maar geen afstand kon doen om er vervolgens theater van te maken. De tekst van Gernaine Tillion had voldoende gemeen met het verhaal van mijn grootvader om er mijn ding mee te kunnen doen en hij stond re
Buchenwald gedeporteerd. Na zijn terugkeer vertelde hij er ons vaak over. Dat was een bepalende invloed tijdens mijn kinden ons bepaalde waarden mee te geven en ons groot te Hijvond thelangijk datjo opkomttegen vlschormen van uitsluiting en haat in de maatschappij.

Was hij actief in het verzet?

Ja, hij was actief in het verzetsnetwerk van Abbé Blanc in Marseille. In augustus 1943 werd hij door de Gestapo gearresteerd.

Ook Germaine Tillion werd gearresteerd voor veretsdaden, zij het in Parijs en niet in Marseille. Ze had onder leiding van Marcel Mauss, de etnoloog. Hij stuurde haar naar het Auress gebergte in Algerije om er onderzoek ons bepald warden mee te een bijzonder originele en boeiende ervaring achter de ug, namelijk toen ze haar doctoraatsverhandeling schreef 
... Ze ontcijferde en beschreef de verbanden tussen de leden van die gemeenschap. Voel je in Verfügbar dat ze dezelfde methodologie toepaste om het functioneren
en het uiteindelijke doel van het kamp te doorgronden? Want ze beschouwde de situatie vanuit het oogpunt van de economische verhouding tussen arbeid, dood en geld.

Ja, je voelt in de tekst haar wetenschappelijke en nalytische achtergrond, en ook dat ze vastbesloten is om de ervaring objectief weer te geven. Ze observeerde oe mensen samenleven. Het hoofdpersonage van akte Heet trouwens 'de natuuronderzoeker'. Het is een

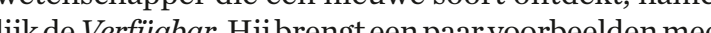
je ve het als de natuuronderzoekers in de negentiende eeuw ( Jel Je veecleiding als etnos. Vilijke toestan de afschuwelijke toestand wanin ze zich bevinden. De natuuronderzoeker toont geen enkele emotie bij wat Verfighar is mager lan nawelijks op zijn benz. De is uitert bizar, blijft zeventen uur per dagoverein.

In andere teksten van overlevenden vind je niet $d$ levendige ironie van Germaine Tillion. Op die manier 作 ratiekampsysteem verbaal en muzkaal bestrijden. Van dergelijk verzet zijn er niet veel andere voorbeelden, tenz misschien in Theresienstadt. Ik denk dan aan Viktor UIImanns opera Der Kaiservon Atlantis oder Die Tod-Verweigerung, waarin de dood capituleert. Of nog Hledám strasidlo (We zijn op zoek naar een spook), het stuk van Hanuš Hachenburg dat onlangs door de onderzoekster Claire Audhuy werd teruggevonden en vertaald. Ook in dat stuk wordt methumor snsot de dictatoriale toestand

Kun je volgens jou in termen van verzet een paralle Trekken met de kunstenaars uit dat getto? Toen Germain Tillion het stuk schreef, was ze nog in goede gezondheid. Ze schatte de overlevingstijd van de gedeporteerden in Ravensbruck op twee jaar, wat alle verhoudingen in ach

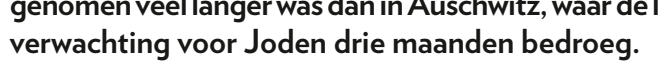

Een mooie beschrijving van de omstandigheden waarin ze aan Verfugbar werkte, vind je in haar stud 'Ravensbrück' Ze schreefhet stukin drie weken tijd. Ze licht toe dat ze het kon schrijven dankzij een samenspel van omstandigheden. Zij en haar commando moesten kleren en voorwerpen sorteren, de oorlogsbuit. De nderen waren solidair en toonden zich bereid om haa deel van het werk over te nemen, zodat zij zich kon verbergen om te schrijven. Dat collectieve gedrag is op zichzelf beschouwd heel bijzonder, want anders had ze niet kunnen schrijven. Langer dan die drie weken had het ook niet gekund, zo zegt ze. Ze was te zeer verwakt, de transporten en selecties werden talrijker Rico werd te zrot. Ze kon gaskaner gebouwd, het werk onttrekken.

Is het gepubliceerde facsimile wel het originele aantekenboekje? Want de precisie van haar handschrift darin is opvallend. Je merkt maar heel weinig doorhalingen, de personages tonen geen enkele aarzeling, het geheel is geordend en logisch, de muzikale verwijzingen en liedjes lijken helemaal op hun plaats. Hoe slaagde Tillion erin om in zo'n korte tijdspanne en op zo'n beheerste wijze een a bij al viij complex verhaal te ontwikkelen? Bereidde ze de tekst voor met behulp van haar medegevangenen of schreef ze hem alleen in een hoekje?

Bepaalde liedjes werden collectief geschreven, elke edeporteerde moest een vers of een zin van het lied aandragen. We weten het niet precies, ze gaf daarover niet veel toelichting. Als de tekst geschreven was, zat het erop. Zoals ze ook uitlegt in haar studie uit 2007 had die tekst een doel, namelijk hen helpen bij het overeven. Dat was voor Germaine Tillion een levensvoorwaarde; ze moesten die omgeving begrijpen, wat de ten te ontmenselijken. Zo konden ze etegen tracht-

De tekst van Le Verüghor zit bordevolwooden die Le Verfügbar zit boordevol woorden di alleen gedeporteerden kunnen begrijpen, zelfs alleen gedeporteerden uit Ravensbrück, want het betreft een interne kampdiscussie. Bepaalde woorden ontstonden Is aangepaste vertalingen van Duitse woorden en he taalgebruik bevat veel humoristische formuleringen of binnendienst voor ut was en de dag in (1) De tricoteuses (breisters) waren vrouwen die in de nachtploegen waren
ingedeeld; de cartes roses (roze kaarten) waren zieken die in het Revier ingedeeld; de cartes roses (roze karten) waren zieken die in het Revier
een arbeidsvrijsteling hadden verkregen. Die twee groepen vrouwen
bevonden zich overdag in de blokhuizen (M.P.). hun blokhuis mocht doorbrengen; de Arbeitseinsatz die Arbeit-Ersatz werd om te doen denken aan een pseudotewerkstellingsbureau; Aspirine in de plaats van Aufzehrin of vrouwelijke wachter; de Bekleidung, de opsagplaats met kleren; de Blockova, Tsjechisch bargoen voor de Blockälteste of de oudste in het blokhuis; Blok 32; Is de vor Bunker onz

Is de tekst met zijn aparte taaltje zonder voorkenni te begrijpen? Hoe sta je tegenover die moeilijkheid? Hos kan de toeschouwer de tekst met al zijn spitsvondigheden begrijpen als hij de betekenis van de gebruikte woorden

Een van de sleutels is dat we de tekst zelf moeten begrijpen. De ochtenden van de eerste repetities heben risch onderzok nar die periode, de opkomstan het risch ond in van de bevolking in ezette gebieden erukking tie in al har vormen. We trebied tie in al haar vormen. We trachtten te begrijpen hoe wjurt daardtraject van een gedeporteerde te ontcijferen en we kijn de tote lijnen, mar elke ervaring is Er zijn de grote lijnen, ma held in dat we vee lizen. verschillend... Onze studie hield in dat we veel lazen. We mosten een gemeenschappelijke bagage hebben en ook teksten waarnaar we konden teruggrijpen. D Jore Semprún Ron Delbo enzovoort.

Misschien is het een goed idee om aan het begin in stilte, een tekst te projecteren met uitleg over Of een document uit te delen, met het risico dat de toeschouwers dat pas na de voorstelling en dus te laat lezen?

Inderdaad, waarschijnlijk moet je die informatie verstrekken, misschien via een lexicon met woorden die de toeschouwers nodig hebben. We zijn van plan ontmoetingen met het publiek te organiseren. Tijdens ontmoetingen met het publiek te organiseren. Tijdens
de discussie na de voorstelling van het work-in-progress in november 2015 besefte ik dat de mensen het moeilijk hebben met de humor en de muziek. Ik vraag me af in hoeverre de tekst het publiek kan doen nadenken, hoe het getuigenis uit die periode ons kan aanzetten to reflectie over wat er vandaag gebeurt. Het herinnering ancover de moet trekken uit het verleden om te vermijden dat vergelijkbare gebeurtenissen zich opnieuw voordoen. Da voor mij de kern van de zaak, hoe je een herhaling van dergelijke gebeurtenissen kunt vermijden

Door de verregaande ironie in de operette van Gerken. Want het stuk is door en door tragisch.

Ik vind het geen komisch stuk. Het is intelligent, s een lange neus aan het adres van het nazisme en naz's. In elk geval breng ik dit stuk niet om de menMet ne Met een poêtische en artistieke aanpak kun je de toeschouwers volgens mij raken, hun een idee geven van hoe het was. Dankzij humor, muziek, marionetten en het host bieden pan de werkilikheid a we

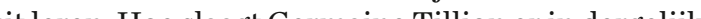
uit leren. Hoe slaagt Germaine Tillion er in dergelijke

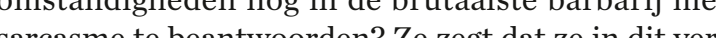
band hear toorden? Ze zegt dat ze in dit verbeste wapen is Ze houdt je humor, omdat dit het tent tend brengt ze bij anderen het verlangen teweeg om te

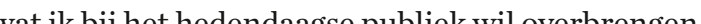

Hoe heb je in het stuk de juiste 'toon' gevonden, het ritme, de energie, maar ook de kracht, die zoals gezegd het gevolg is van het 'kluchtige aspect, het co
chelijk maken van die hallucinante wereld?

Er zijn al een paar opties, maar we blijven zoeken Belangrijk is vooral de juiste afstand tussen de actrices en hun personage. De vraag was: hoe de gedeporverd voordoen als gedeporteerden. De actrices moeten de die kwe van de getuigen vertolken. We zijn lang met die kwestie bezig geweest en uiteindelijk hebben we Tillion geopteerd om de rolverdeling van Germaine The personages die telkens overeenstemmen met een van mo erschillende rolverdeling. Bij Germaine Tillion zijn er een tiental gedeporteerden, die overeenkomen me Bedegedeporteerden.

Belangrijk in het verloop van de tekst is de evolutie viduen te onderscheiden zijn, naar figuren die gaande- ... 
œ weg een individueel karakter krijgen. Op de lange duu aat het publiek figuren meteen aparte persoonlijkheid herkennen. Het proces is tegengesteld aan dat van de naz"s, die mikten op het verdijnen van individuen. Daarom leek het me belangrik dat elke actrice aan de slagging met wat we onder elkaar hun 'Verfugbar-perover over de kou, maar beelden die nooit uit. Met behulp die de kou verbeelden.

Er is veel onderzoek gedaan naar de kwestie van het onbeschrijfelijke karakter van de concentratiekampervaing. Het mag dan lastig zijn om menselijke ervaringen volledig te beschrijven, toch hebben gedeporteerden en volle

Op het podium moet je volgens mij voelen dat het om niet voor de hand liggende woorden gaat. In het

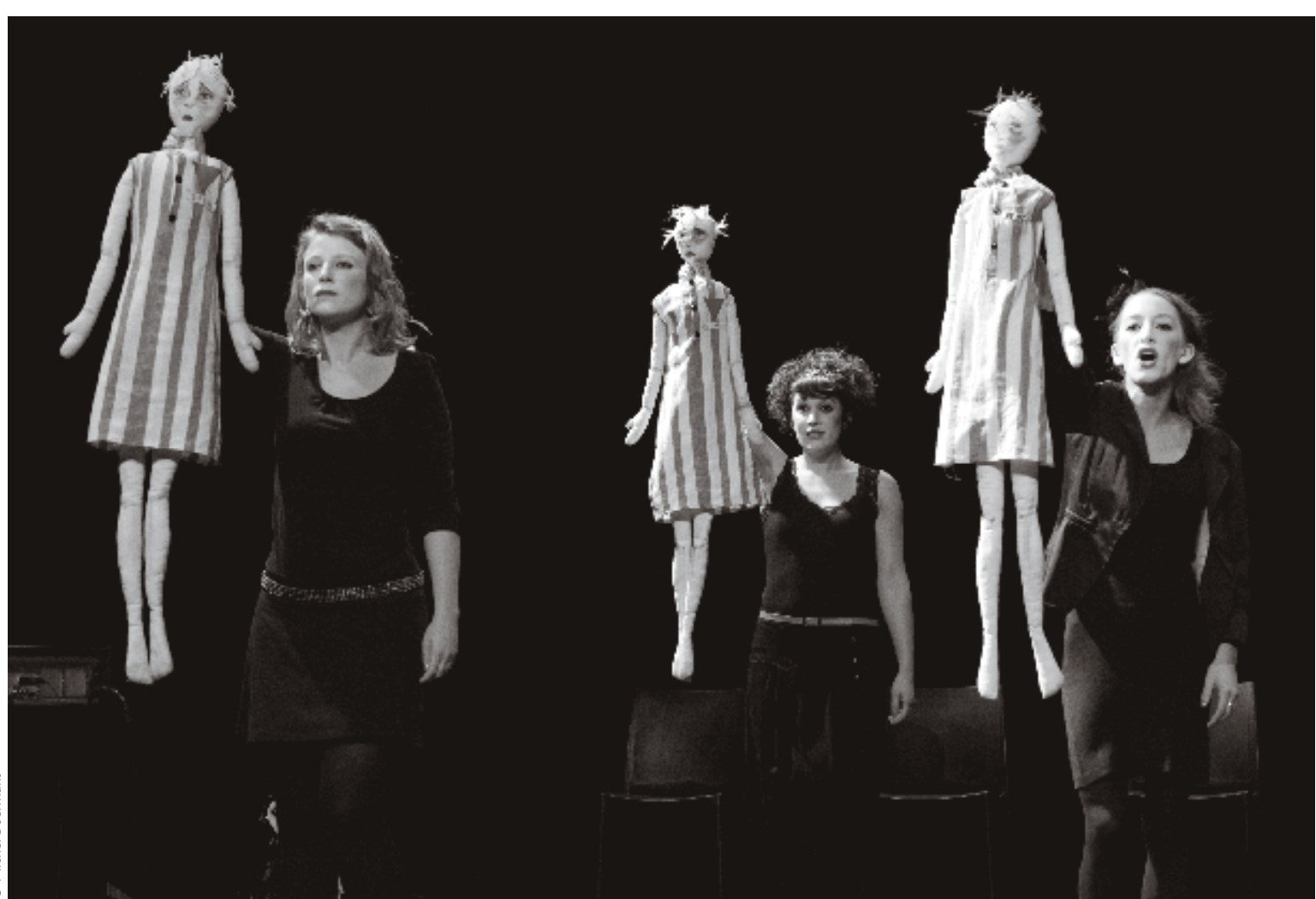
poitie Ze metsbare nooit echt naar terug. Iets dergelijks vind je trouwen team zitten geen poppenspeelsters of zangeressen, het zijn actrices. Het is een waagstuk met zijn eigen positie. Ze moeten ande vaijn. $O$ de dat de wanil dat de zaken kwetsbaar zijn, kwetsbaar maar onde erinhoudelijk iets niet in de hak zou zijn.

Als de actrices elektrische gitaar spelen, bevinden ze zich in dezelfde wereld als de toeschouwers, en dus niet in de kampen. Maar nogmaals, hoe kunnen de toeschouwers egrijpen?

Met het decorontwerp - dat in het work-in-progres heel schetsmatig was - willen we geen concentratiekamp nabootsen, maar een realiteit oproepen zonde det podium weer te geven. Het ver政 ken merk je iets als een bevlieging: de gedetineerde maken grapjes, ze prikkelen hun verbeelding door regonale gerechten te beschrijven... Maar in twee of drie replieken sluiptdegruwel tochweer binnen. Er is altij enand dere

Het is interessant on wet die dubber the Het is interessant om met die dubbelheid te werken: uitdrukkinggeven aan het leven, levendig en mooi enzelfs onderhoudend zijn tegenover de gruwelvan concentratiekampen. Als je kijkt naar getuigenissen ung werd getröten door de getuigenissen van vrouwen in ravens wilde ik ween

Germaine Tillion vervulde haar functie als toeveraat door de operette Orphée aux enfers van Offenbach te parodiëren, die ook weer een parodie was op Orfeo Orphe vitice van Gluck. Elgenlijk speelde ze de rolvan Orpheus: uit de helvan Ravensbruck hoopte ze haar a zij

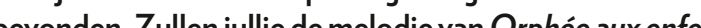
spelen?

Dat is de bedoeling, ja. Op een bepaald moment helemaal in het begin van akte 3 , laat Tillion zich daardoor inspireren. Aan haar manier van schrijven merk je trouwens har ver ysieke toestand. De eerste akte is heel levendig, me bijzonder meeslepende lied jes. Hij is veel krachtiger en langer dan de andere twee. Geleidelijk aan worden de dat Germaine Tillion aflegt.

We komen stilaan aan het einde van dit gesprek. Welke boodschap wil je de toeschouwer meegeven? (lacht)

Het is geen optie om je ogen te sluiten voor barbarij of, nog erger, te gaan collaboreren. Mensen als Germaine Tillion kozen ervoor om zich te verzetten en te vechten tot de laatste snik, nadat ze eerst soliwe willen dat dergelijke acties vaker voorkomen en ook bij Germaine Tillion. In de bewegingen op de planake In elfs, waarom niet, de norm worden, dan moeten we zu meteen beginnen met nee te leren zegoen tegen de logica van uitsluiting en haat. We moeten waakzaam lijven en geen kleine toegevingen doen. Dat is simpelpolitici die willen dat vluchtelingen kentekens drage Hebben we dat niet al eens meegemaakt? Hoe is het mogelijk dat we de lessen van de geschiedenis dreigen te vergeten? Het is onze burgerplicht on waakzaam deilstekens leren herkennen.

Je moet wat er nu gebeurt inderdaad verbinden met vorbelden uit het verleden waakzaam blijven en nadenvoorbeelden uit het verleden, waakzaam blijven en nadenren Mikje ook op en schoopubliet? je ook op een schoolpubliek?

De voorstelling is bedoeld voor alle publieken en we zijn een waarborg voor de toekomst. Met het schoolpubliek zou ik graag aan reflectie en sensibilisering doen. Voorafgaand aan de voorstelling houden we een reeks is ze niet gen. als ze niet een ninin stelling zullen gericht zijn op de verbande

\section{$\rightarrow$ Meer weten}

$\Leftrightarrow$ Germaine Tillion, Le Verfügbar aux enfers. Une opérette à

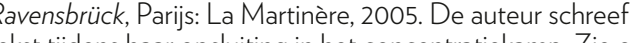
. Productie: Les Souffleuses de Chaos Regie: Marion Pillé Muziek: Simon Besème Actrices: Aurore Lacrosse, Sophie Maréchal, Marion Nguyen $\Delta$ Er zijn voorstellingen gepland in het Théâtre Marni in weg een zaak van ethiek en burgerschap. Er zijn no willen ook scholen en jongeren uitnodigen, want die whorije ateur en voor- 